\title{
AVALIAÇÃO DO ENRIQUECIMENTO DE CAPOEIRA POR MEIO DE SEMEADURA DIRETA DE MOGNO E CEDRO
}

Paulo Eduardo Barni

Professor DSc. da Universidade Estadual de Roraima (Campus Rorainópolis) - UERR

Paulo.eng.flor@uerr.edu.br

\section{Narrúbia Oliveira de Almeida Martins}

Professora DSc. da Universidade Federal do Amazonas - UFAM

nalmeida@ufam.edu.br

\section{RESUMO}

As áreas desmatadas na Amazônia brasileira, devido à baixa fertilidade, sãoutilizadas e logo abandonadas pelos agricultores e fazendeiros, se transformando rapidamente em capoeiras. Estas podem ser recuperadas com reflorestamentos, utilizando-se técnicas de enriquecimento. Sendo a semeadura direta no campo uma opção. O presente estudo teve como objetivo avaliar a semeadura direta em enriquecimento de capoeira utilizando-se mogno e cedro. 0 experimento foi divididoem três etapas: a) laboratório;b) viveiro e; c) campo. Em laboratório o mogno obteve 31\% de germinação e IVG de 0,550; o cedro obteve $71,0 \%$ de germinação e 2,215 de IVG. Na fase de viveiro (50,0 \% de retenção solar) o mogno obteve emergência de $83,5 \%$, e IVE de 0,863 . O crescimento em altura foi de $29,7 \mathrm{~cm}$ e $5,0 \mathrm{~mm}$ em diâmetro. O cedro obteve $67,0 \%$ na emergência e 1,187 para o IVE. O crescimento foi de $15,6 \mathrm{~cm}$ e $5,4 \mathrm{~mm}$ de diâmetro. A emergência do mogno no campo foi de $54,76 \%$, mortalidade de 9,4\% e sobrevivência de 91,6\%a 106 dias após semeadura. A altura média total alcançada pelo mogno foi de $18,9 \mathrm{~cm}$ e $3,20 \mathrm{~mm}$ para o diâmetro.A emergência do cedro no campo foi de $30,5 \%$, a mortalidadede $36,4 \%$ e sobrevivência de $63,6 \%$ no mesmo período. A altura média total alcançada pelo cedro foi de $9,0 \mathrm{~cm}$ e $3,2 \mathrm{~mm}$ para o diâmetro. Considerando os resultados alcançados o sistema de enriquecimento de capoeira por semeadura direta de mogno e cedro temgrande potencial de viabilidade no campo.

Palavras - chave: Áreas degradadas, herbivoria, desmatamento, fronteira agropecuária.
Las áreas deforestadas en la Amazonia brasileña, debido a la baja fertilidad, son utilizadas y luego abandonadas por los agricultores y granjeros, transformándose rápidamente en capoeiras. Estas pueden ser recuperadas con reforestaciones, utilizando técnicas de enriquecimiento. Siendo la siembra directa en el campo una opción. El presente estudio tuvo como objetivo evaluar la siembra directa en enriquecimiento de capoeira utilizando caoba y cedro. El experimento se dividió en tres etapas: a) laboratorio; b) vivero y; c) campo. En laboratorio la caoba obtuvo 31\% de germinación y IVG de 0,550; el cedro obtuvo $71 \%$ de germinación y 2,215 de IVG. En la fase de vivero ( $50 \%$ de retención solar) la caoba obtuvo una emergencia del 83,5\%, y IVE de 0,863. El crecimiento en altura fue de $29,7 \mathrm{~cm}$ y $5,03 \mathrm{~mm}$ en diámetro. El cedro obtuvo $67 \%$ en la emergencia y 1,187 para el IVE. El crecimiento fue de $15,6 \mathrm{~cm}$ y $5,44 \mathrm{~mm}$ de diámetro. La emergencia de la caoba en el campo fue de $54,76 \%$, mortalidad del $9,4 \%$ y supervivencia del $91,6 \%$ a 106 días después de la siembra. La altura fue de $18,9 \mathrm{~cm}$ y $3,20 \mathrm{~mm}$ para el diámetro. La emergencia del cedro en el campo fue del $30,5 \%$, la mortalidad del $36,36 \%$ y la supervivencia del $63,64 \%$ en el mismo período. La altura fue de $9,0 \mathrm{~cm}$ y 3,21 mm para el diámetro. Considerando los resultados alcanzados el sistema de enriquecimiento de capoeira por siembra directa de caoba y cedro tiene gran potencial de viabilidad en el campo.

Palabras clave: Áreas degradadas, herbivoria, deforestación, frontera agropecuaria. 


\section{INTRODUÇÃO}

Na Amazônia e em toda faixa tropical, o sistema de agricultura de queima e roça é praticado intensamente por agricultores familiares, fazendeiros, pequenos criadores e colonos em Projetos de Assentamento PA. Essa ocupação desordenada, em plantios sucessivos, causa a exaustão do solo e sua consequente degradação e abandono pelas populações locais. Este sistema assemelha-se aos sistemas de corte e queima praticadopor indios em agricultura itinerante de coivara (LAMPRECHT, 1990; MELATTI, 1993; PENEIREIRO, 2002; GEHRING, 2005).

Nessas áreas abandonadas, começa, então, um processo lento de regeneração natural, que segundo Mattei \& Rosenthal (2002), em alguns anos atinge a fase de capoeirinha e, ao evoluir, se transforma em capoeira, capoeirão e, num futuro muito distante, poderá vir a formar novamente uma floresta clímax.

Para melhor aproveitar estas áreas de capoeira podem-se utilizar técnicas de enriquecimento. Que consiste na introdução deespécies arbóreasde valor econômico ou não, e que não estão presentes no local pela regeneração natural.

A semeadura direta no campo é uma das técnicas mais promissoras nos processos de regeneração de áreas degradadas quando um dos objetivos é a redução de custos. Pois, toda infraestrutura usada para a produção de mudas, transporte e plantio das mesmas seria eliminada; demandando, portanto, menos pessoal e tempo para se executar a semeadura direta (SANTOS Jr. 2000; BRIENZA Jr. 2003). Shneider et al.(1999), ao compararem a semeadura direta à campo com o plantio usando sementes e mudas de Dodonaea viscosa (L.) Jacq., não encontraram diferença significativa entre os dois sistemas de implantação de florestas.

Na região amazônicao uso da técnica de semeadura direta é ainda pouco conhecida ou utilizada, principalmente pela falta de conhecimento sobre a auto-ecologia da maioria das espécies florestais (CAMARGO et al. 1998).

Este estudo teve como objetivo avaliar a semeadura direta no enriquecimento de capoeira utilizando-se duas espécies de valor econômico: mogno (Swietenia Macrophylla King) e cedro (Cedrelaodorata L.). Sendo estas duas espécies ocorrentes na Amazônia.

\section{MATERIAL E MÉTODOS}

\section{Área de estudo}

Os experimentos (fases de laboratório e viveiro florestal) foram conduzidos nas dependências do campus universitário (Faculdade de Ciências Agrárias - FCA) e a fase de campo na fazenda experimental da Universidade Federal do Amazonas, localizada no km 38 da BR - 174 (Figura 1) que liga Manaus a Boa Vista, capital de Roraima.

\section{Laboratório}

Os testes foram instalados em câmara de germinação, regulada entre $25-300 C$ sob luz branca contínua e areia lavada e esterilizada como substrato, em vasilhames de vidro tipo pirex. Por 30 dias foram coletados dados de germinação, que permitiu o cálculo do indice de velocidade de germinação (IVG) e a percentagem de germinação.

\section{Viveiro}

Os testes em viveiro florestal foram instaladoscom $50 \%$ de retenção solar. O substrato utilizado foi terra vegetal e barro, de dois para um, em sacos plásticos de $3 \mathrm{~kg}$ e durante 40 dias foram coletados dados de emergência. Usaram-seduassementes por embalagem. Onde houve emergência 
de mais de uma plântula procedeu-se um desbaste de modo a ficar somente um individuo por embalagem. Os dados de emergência foram coletados em todos os recipientes. Já os dados de crescimento em altura $(\mathrm{cm})$ e diâmetro $(\mathrm{mm})$,foram coletados semanalmentenascincoplântulas dentro de cada repetição, evitando efeitos de borda e foram registrados num intervalo temporal de 122 dias para o mogno e 143 para o cedro.

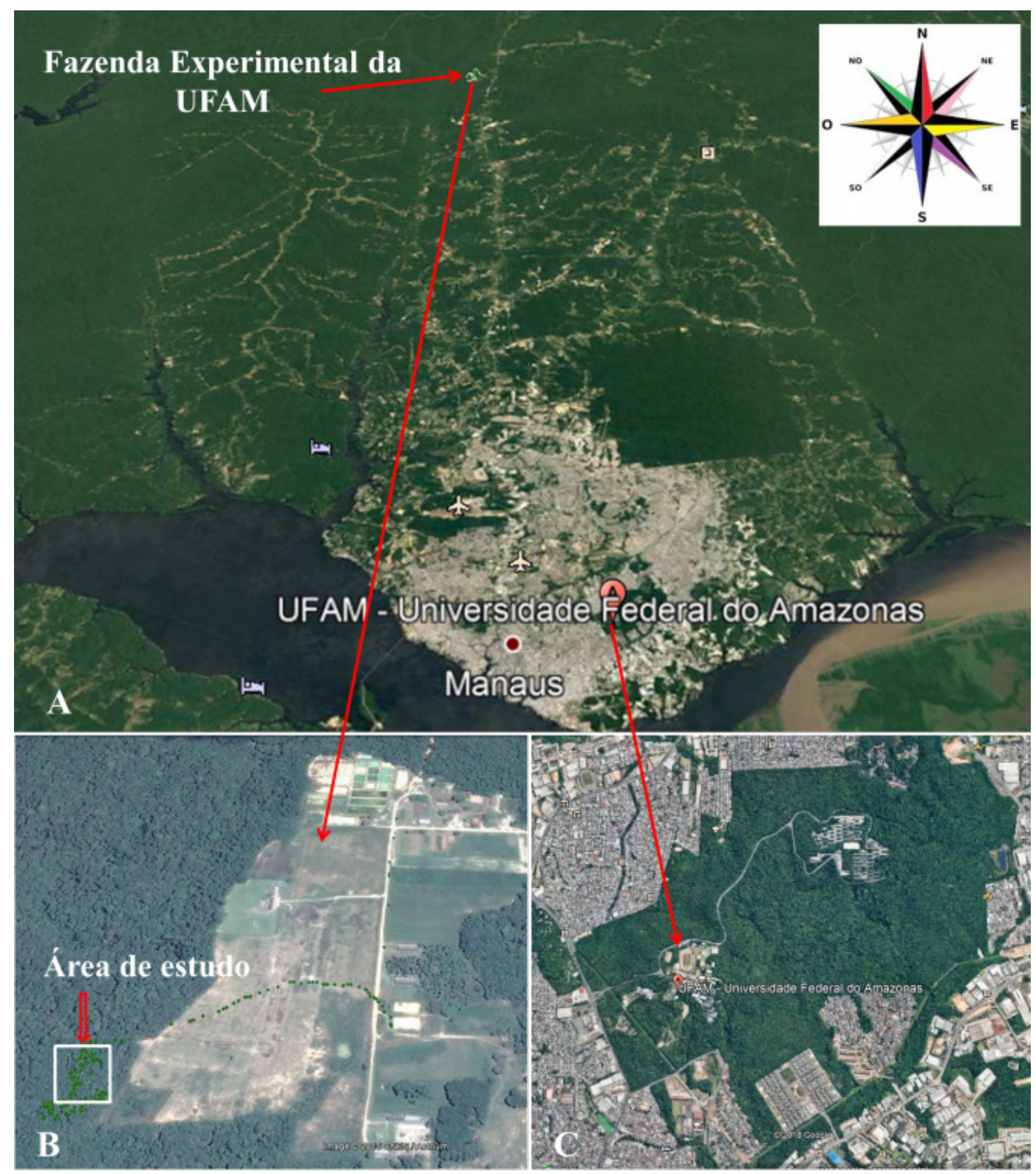

Figura 1: Locais de desenvolvimento da pesquisa(A). Em (B) Fazenda Experimental e em (C) Campus da UFAM. Fonte: Google Earth, 2018. 


\section{Campo}

As covas foram cavadas com cavadeiras tipo "boca-de-lobo" em picadas (linhas) abertas na capoeira.Logo após,procedeu-se àincorporação da cal e do adubo junto ao substrato das covas.Para isso, utilizou-seuma caixa de madeira, uma pá e uma enxada para homogeneizar o adubo e a cal ao substrato da cova dentro da caixa e retornar o material homogeneizado para dentro da cova. O "kit" de adubo consistia de 29,18g/cova decalcário; $272,92 \mathrm{~g} /$ cova de superfosfato triplo e $24,54 \mathrm{~g} /$ cova de FTE BR12, equivalentes a $2500 \mathrm{~kg}$ de calcário por ha.

O dimensionamento das covas foi de $50 \times 50 \times 50 \mathrm{~cm}(125000 \mathrm{~cm} 3)$, onde a semeadura foi realizada diretamente. Alternou-se uma cova de mogno e outra de cedro, com $5 \mathrm{~m}$ entre linhas e entre covas, com 12 covas por linha. As covas foram piqueteadas, utilizando-se de material encontrado no próprio local e foram semeadas sete sementes por cova.

Nastrêsprimeiras

emergências das plântulas foram acompanhadas por duas avaliações semanais, depois passaram a ocorrer apenas uma vez por semana, tanto para a emergência como para a mortalidade. Dados de crescimento e diâmetro passaram a ser coletados semanalmente a partir de 128 dias após semeadura nas plântulas mais vigorosas de cada cova, se estendendo até 181 dias após semeadura.

As possiveis causas da mortalidade no campo foram analisadas sob três aspectos: herbivoria, causas ambientais e outros. Para os cálculos de porcentagem de germinação, emergência, mortalidade, regeneração, etc. foi usada a fórmula geral:

Germinação(\%) = Sementes Germinadas x 100 / Total de Sementes.

\section{RESULTADOS E DISCUSSÃO}

\section{Laboratório}

Os resultados com o mogno não foram satisfatórios. Houve problemas, provavelmente, com o compartilhamento da câmara de germinação com outro experimento em andamento no mesmo local. Este fato pode ter ocasionado a contaminação das sementes por fungos e, provavelmente, justificaos baixos percentuais de germinação $(31,0 \%)$ registrados para o mogno e índice de Velocidade de Germinação - IVG de 0,550. Ao contrario do mogno, osresultados para o cedro foram satisfatórios, alcançando um percentual de germinação de 71\%e IVG de 2,215. Estes resultados estão dentro dos padrões aceitáveis para a espécie (Figura 2), no entanto, ficaram abaixo dos valoresencontrados por Almeida (2004), em condições semelhantes.

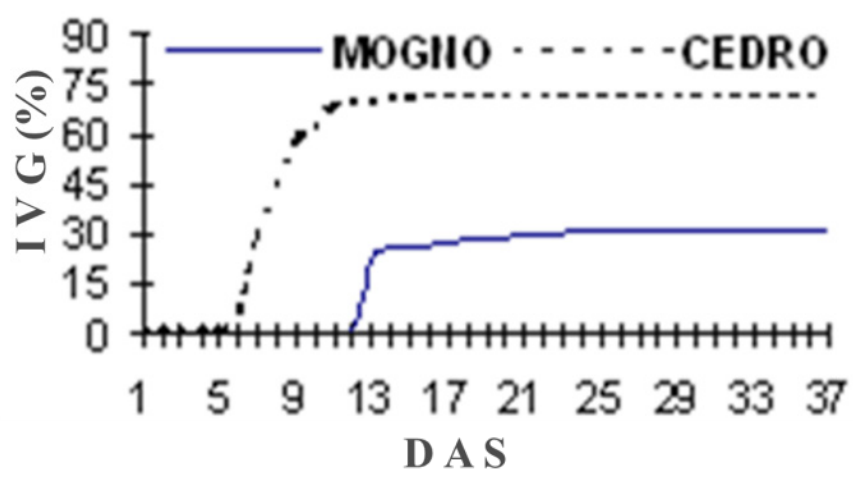

Figura 2: Índice de Velocidade de Germinação -IVG(\%) para o mogno e o cedro obtidas em laboratório, a 37 Dias Após a Semeadura - DAS. Fonte: autores, 2017.

\section{Dados de Mogno e cedro casa de vegetaçãoa $50 \%$ desombreamento}

A emergência do mogno se verificouaos 15 dias após a semeadura, se prolongando por mais 11 dias. Os resultados de percentagem de emergência obtidos foram de $83,5 \%$ e o IVE foi de 0,863, bastante superiores aos alcançados em laboratório, invertendo as 
curvas de emergência também em relação aocedro. Considerando a avaliação das sementes de cedro foi verificada a primeira emergência aos sete dias após a semeadura e prolongou-se por 13 dias (Figura 3). No final do período o cedro alcançou $67 \%$ de emergência e IVE de 1,187. Estes valores foram menores daqueles obtidos em laboratório. Inferiores até daqueles obtidos por Almeida (2004), em seu tratamento testemunha e em condições semelhantes.

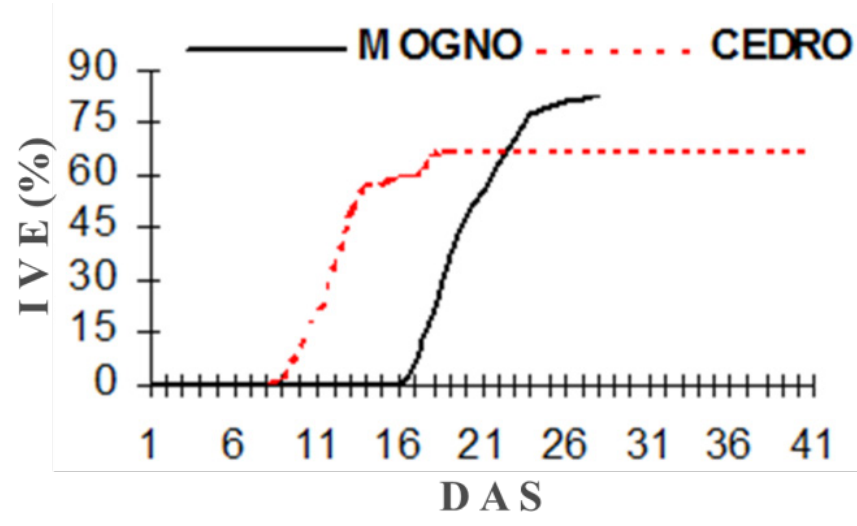

Figura 3: Índice de Velocidade de Emergência -IVE (\%) para o mogno e o cedro obtidas em casa de vegetação com sombreamento a $50 \%$ a 41 Dias Após a Semeadura - DAS. Fonte: autores, 2017.

\section{Altura e diâmetro}

As plântulas de mogno obtiveram incremento médio em alturade $9,3 \mathrm{~cm}$ e de 2,4 $\mathrm{mm}$ para o diâmetro. A altura média no início das avaliações foi de $20,4 \mathrm{~cm}$ e $2,6 \mathrm{~mm}$ para o diâmetro do coleto, respectivamente (Figura $4 \mathrm{~A})$. Estes resultados foram superioresaos de Silva (2004), em condições semelhantes. Dados de altura e diâmetro do coleto do cedro começaram a ser coletados aos 42 dias após a semeadura e se repetiram, semanalmente, durante 143 dias. 0 incremento médio alcançando no período foi de $9,3 \mathrm{~cm}$ para a altura e 3,7 mm para o diâmetro (Figura 4B).
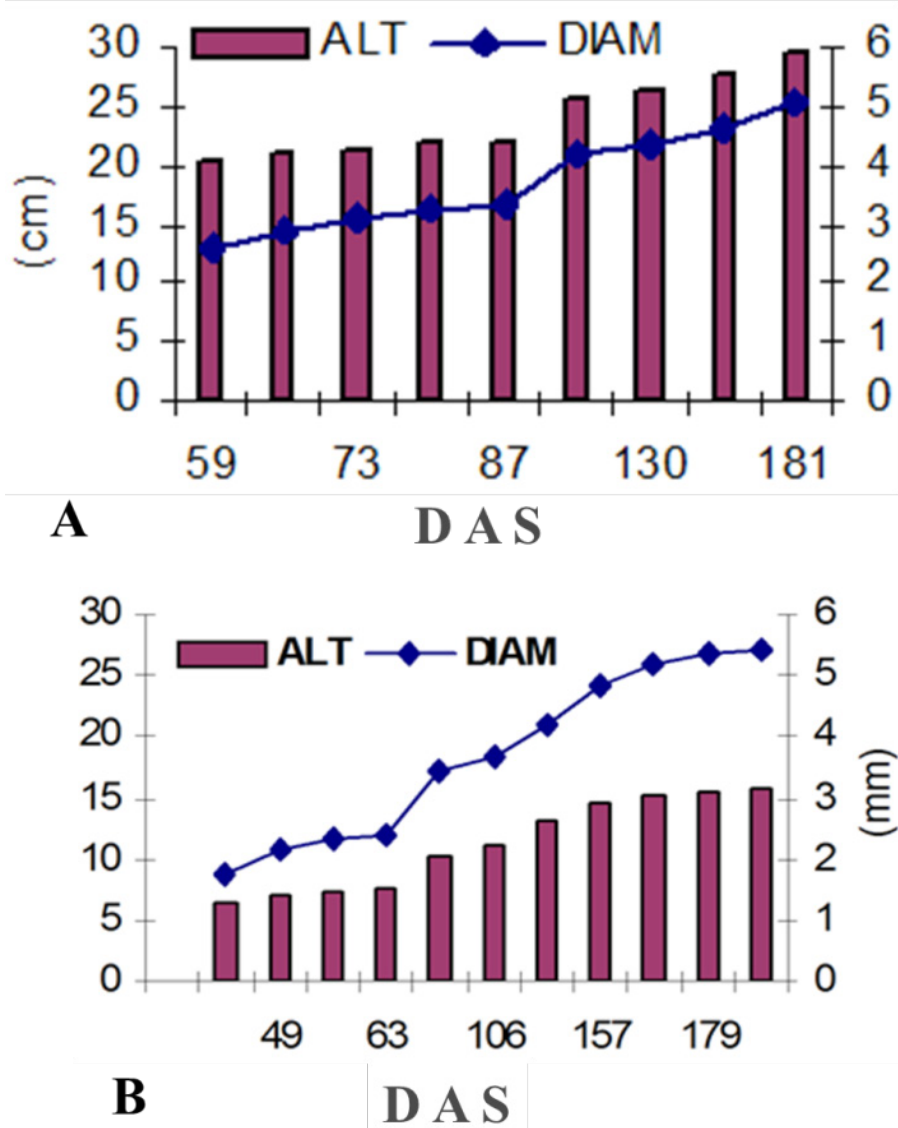

Figura 4: Crescimento em altura $(\mathrm{cm})$ e diâmetro $(\mathrm{mm})$ do mogno (A)e do cedro (B) obtidos em casa de vegetação com sombreamento a 50\%, a 181 dias após semeadura. Fonte: autores, 2017.

\section{Dados de emergência e mortalidade do mogno e cedro em} campo

Aos 18 dias após semeadura foi verificado $0,59 \%$ de emergência das sementes de mogno, alcançando, em 47 dias de avaliação, um percentual final de 54,76\% (Figura 5). Em apenas duas covas não houve emergência $(2,8 \%)$. Ao contrário do cedro, o mogno resistiu bem aos ataques por herbivoria, se regenerando com facilidade, provavelmente, devido ao tamanho da semente que permitem maiores quantidades de reservas nutricionais à plântula.

Aos 106 dias após semeadura foram registradas apenas três covas de mogno sem 
plântulas (4,3\%), havendo a perda de apenas uma cova $(1,43 \%)$ das que houve emergência. As perdas totais de plântulas somaram-se apenas 26 , o que dá um percentual de $9,4 \%$, de 276 sementes emergidas. As possiveis causas da baixa emergência do mogno no campo podem ser as mesmas atribuídas às sementes de cedro, uma vez que as sementes de ambas as essências foram armazenadas juntas e tiveram o mesmo manuseio e sofreram os mesmos estresses.

Considerando as sementes de cedro aos 11 dias após a semeadura, verificou-se 7,3\% de emergência das sementes,com percentual alcançado no final de 72 dias após a semeadura de 30,5\% (Figura 5). As emergências se deram em um intervalo de 20 dias e observou-se 11 covas sem qualquer emergência de plântulas, perfazendo $15,3 \%$ do total de covas.

Essa baixa emergência pode ser explicada, talvez, pela profundidade de semeadura na cova, uma vez que a mesma foi realizada manualmente e com solo saturado pela umidade. Pode ter havidocompactação do solo argiloso sobre as sementes devido às fortes chuvas observadas no local logo após a semeadura direta (p. ex., OLIVEIRA \& FERRAZ, 2003). Brum et al. (1999), testando emergência e sobrevivência de Pinus taeda L. em semeadura direta a diferentes profundidades, relataram que as sementes podem sofrer maior desgaste fisiológico com semeadura mais profunda. É possivel que nestes casos emerjam plântulas debilitadas e consequentemente com menor capacidade de sobrevivência (BRUM et al. 1999).Também Oliveira et al. (2006) constataram redução na germinação de sementes à medida que se aumentava a profundidade de semeadura em campo, o que poderia estar associada à menor disponibilidade de oxigênioem maiores profundidades do solo ou à barreira naturalimposta pelo próprio substrato.

Uma outra possivel causa para a perda de vigor neste lote de sementespode ser explicada, provavelmente, pelas condições de armazenamento das sementes. Houve fortes temporaisocasionando cortes sucessivos no fornecimento de energia elétrica, deixandoas sementes sem condições adequadas de armazenagempor até três dias.E são a temperatura e a umidade do ar os principais fatores que afetam a qualidade fisiológica da semente, em particular o seu vigor, durante o armazenamento(CARVALHO \& NAKAGAWA 1980; VIEIRA et al., 2001; FLORIANO, 2004). Carvalho et al. (2006) recomendaram a temperatura de -18으 para o armazenamento da maioria das sementes secas de espécies florestais encontradas na região de Lavras - MG.

Não se pode descartartambém, a possibilidade de ter havido predação das sementes por formigas. De acordo com Hau (1997) pequenas sementes $(<0,02 \mathrm{~g})$ são mais vulneráveis ao ataque de formigas de fogo (Solenopsissp.), formigas cortadeiras (Atta sexdens) e formigas colhedeiras (Pheidolesp.) do que sementes grandes( $>5 \mathrm{~g})$. Crawley (1989), diz que os ataques de insetos herbívoros podem afetar o desempenho das plântulas quanto ao crescimento, forma, taxa de desenvolvimento e na sobrevivência das mesmas.

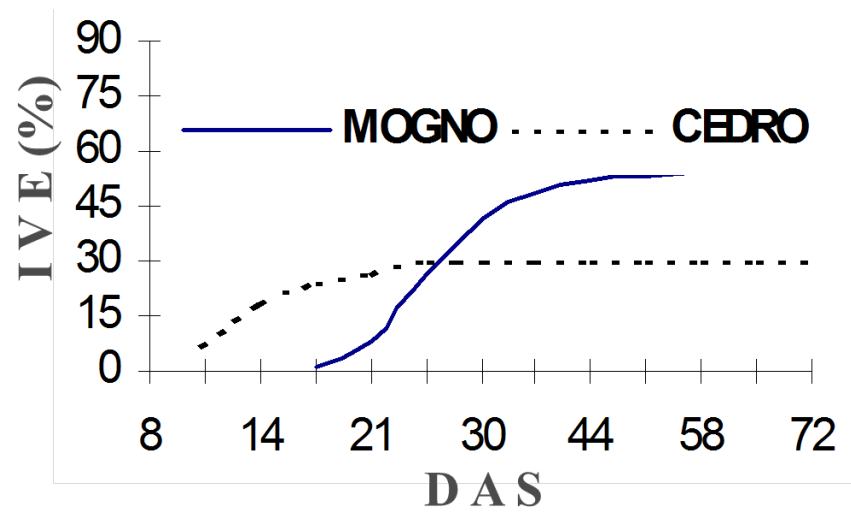

Figura 5: Curvas de percentagem de emergência de plântulas de mogno e cedro obtidas em campo 72 dias após a semeadura. Fonte: autores, 2017.

Considerando os dados de mortalidade do mogno (9,4\%) aos 106 após a semeadura, foram assim divididos: herbivoria $85,0 \%$ das perdas, causas ambientais com $11,0 \%$ 
das perdas e outros, com $4,0 \%$ do total de perdas. 0 percentual de perdas, somente sobre aquelas plântulas atacadas (58), foi de 44,8\%. Essas perdas foram registradas em 27 covas, ou em $38,0 \%$ do total de covas (72). A mortalidade do cedro foi de 36,4\%, aos 106 dias após semeadura (Figura 6), e observouse 29 covas sem plântulas (40,3\%). Houve ataquesem 44 covas (72,1\%), com perdas de 18 covas (29,5\%). 0 total de plântulas de cedro atacadas de alguma forma foram em numero de 85 , o que dá um percentual de $55,0 \%$ de ataques sobre as sementes que emergiram. Dessas 85 plântulas atacadas, 56 morreram (65,9\%). As possiveis causas dessa mortalidade foram assim distribuídas: herbivoria $59,0 \%$ das perdas, causas ambientais $30,0 \%$ das perdas e outros com $11,0 \%$ do total de perdas.

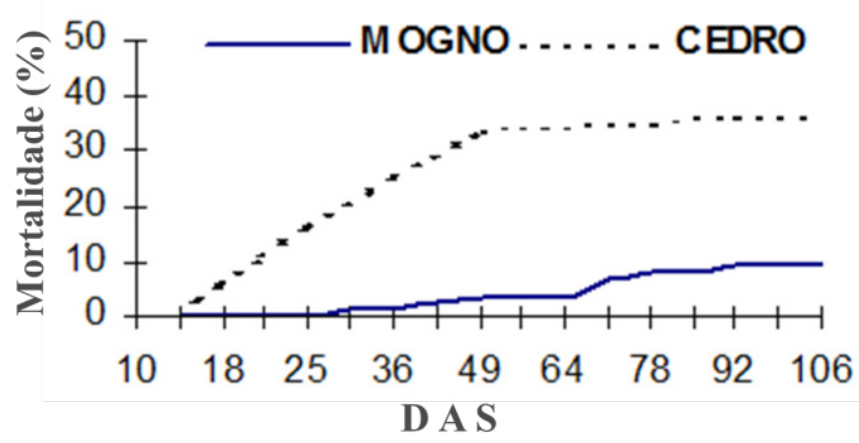

Figura 6: Curvas de percentagem de mortalidade de plântulas de cedro e do mogno obtidas em campo 106 dias após a semeadura. Fonte: autores, 2017.

Sem dúvidas os ataques por herbívoros foram os maiores causadores da mortalidade de plântulas no campo, tanto de mogno como do cedro. Muitos ataques se davam, possivelmente por formigas cortadeiras, que cortavam as plântulas acima do coleto, tombando-as, cortando também suas folhas. Crawley (1989), estudando insetos herbivoros e sua dinâmica na população de plantas, afirma que insetos herbivoros podem afetar a performance das plantas em muitos aspectos. Dentre eles, o autor destaca os efeitos no crescimento, competição, forma, produção de sementes, taxa de desenvolvimento e sobrevivência. Houve casos em que plântulas de mogno secaram completamente, precedidas por murcha das mudas, ao lado de outras plântulas sadias, sem sinais aparentes de ataques.

Na fase de emergência também houve predação das plântulas de mogno, provavelmente, por roedores, que arrancavam as plântulas na cova e comiam as reservas das sementes. Veríssimo \& Grogan (2002) relatam que animais como paca e pequenos roedores são conhecidos por comerem as sementes de mogno no chão. Estas sementes grandes estão sujeitas à predação por insetos, pássaros e roedores (ALMEIDA, 2004). Crawley (1989) afirma que moluscos e herbívoros vertebrados são considerados os maiores predadores de plântulas. Para Hau (1997) a predação de sementes por pequenos roedores em encostas de pastagens e capoeiras pode reduzir a disponibilidade de sementes de árvores para regeneração.

\section{Regeneração}

A regeneração se obtém por diferença entre o total de plântulas que foram atacadas e o total das que efetivamente morreram. No caso do mogno 26 plântulas sobreviveram aos ataques, representando percentual de regeneração de 55,2\%. Considerando o cedro, este obteve percentual de regeneração inferior ao do mogno, registrando-se percentual de regeneração de $34,1 \%$, ou seja, sobrevivendo 26 plântulas de um total de 85 atacadas em campo.

\section{Dados de crescimento em altura e diâmetro do mogno e cedro em campo}

As coletas dados de crescimento em altura $(\mathrm{cm})$ e diâmetro $(\mathrm{mm})$ do mogno e do cedro em campotiveram inícioaos 128 dias 
após semeadura e com término aos 181 dias. 0 mogno registroualtura total média de $18,9 \mathrm{~cm}$ e $3,2 \mathrm{~mm}$ para o crescimento do diâmetro docoleto, respectivamente (Figura $7 \mathrm{~A}$ ). No mesmo período de 181 dias após a semeadura o cedro alcançou 7,6 cm de altura total média e 2,4 $\mathrm{mm}$ para o diâmetro do coleto (Figura 7B).

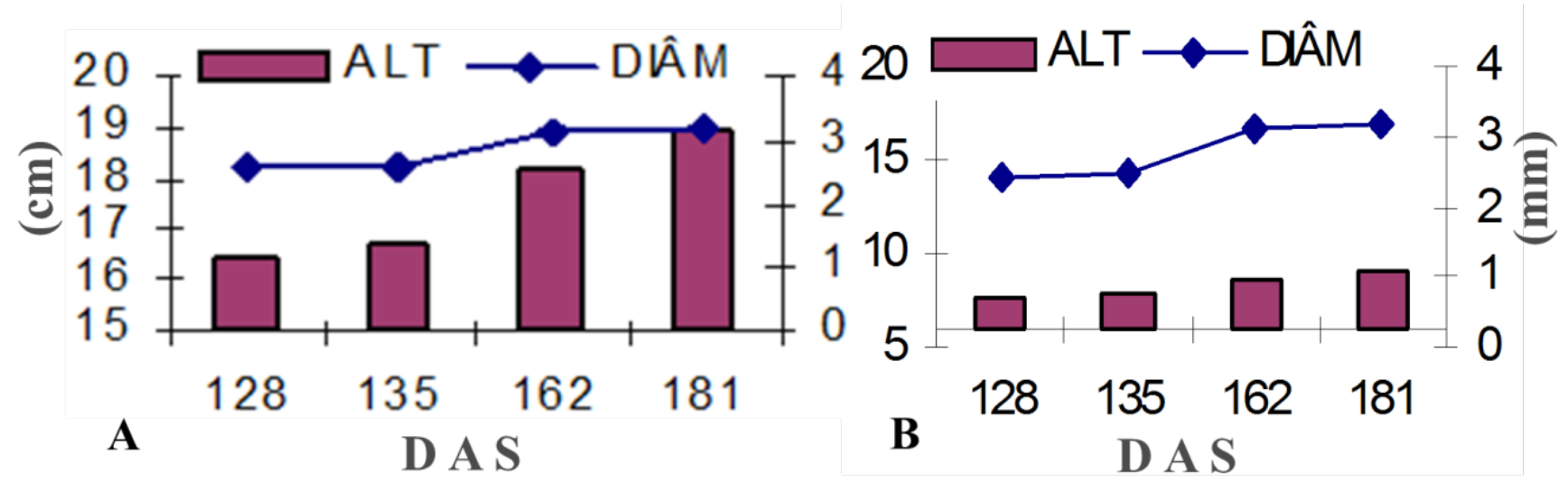

Figura 7. Curvasde crescimento em altura $(\mathrm{cm})$ e diâmetro $(\mathrm{mm})$ do mogno $(A)$ e cedro $(B)$ nacapoeira, aos 181 dias após semeadura.

\section{CONCLUSÕES}

Omogno teve um ótimo desempenho em campo alcançando um índice de 90,6\% de sobrevivência aos 181 dias após semeadura. No entanto o cedro apresentou um desempenho apenassatisfatório na capoeira, alcançando índice de sobrevivência de $63,6 \% .0 s$ inimigos naturais do mogno nessa fase de estabelecimento das plântulas foram formigas cortadeiras e pequenos roedores. Considerando o estabelecimento de plântulas de cedro os principais obstáculos foramformigas cortadeiras e outros insetos não identificados, juntamente comcausas ambientais, aliados, provavelmente, a uma baixa viabilidade genética das sementes. Conclui-se que a semeadura direta em enriquecimento de capoeira pode ser uma técnica com grande potencial de viabilidade, considerando os bons resultados alcançados.

\section{BIBLIOGRAFIA}

ALMEIDA, N. O. Implantação de matas ciliares por plantio direto utilizando-se sementes peletizadas. Tese (Doutorado em Engenharia Florestal). Lavras: UFLA, 2004. 269 p.: il.

BRIENZA Jr., S. Uso de árvores leguminosas para melhorar a agricultura familiar da Amazônia oriental brasileira. Belém, PA: Embrapa Amazônia Oriental. Circular Técnica 32, 2003.

BRUM,E.S.; MATTEI, V. L.;MACHADO, A. A. Emergência e sobrevivência de Pinus taedaL. em semeadura diretaa diferentes profundidades. Rev. Bras. de AGROCIÊNCIA v.5no3, 190-194. 1999

CAMARGO, J.L.C.; FERRAZ, I. D.K.; IMAKAWA, A.M. Estabelecimento de plântulas de 
espécies florestais por semeadura direta e longevidade do banco de sementes em áreas naturais e degradadas da Amazônia central. In: Pesquisas florestais para conservação da floresta e reabilitação de áreas degradas da Amazônia.Manaus: MCT.INPA/JICA.INPA. AM.ISBN: 85.7401.030-8. 1998. p. 201 - 214.

CARVALHO, L. R.; SILVA, E. A. A. \& DAVIDE, A. C. Classificação de sementes florestais quanto ao comportamento no armazenamento. Partea dissertação de mestrado do primeiro autor apresentada à Universidade Federal de Lavras (UFLA). Revista Brasileira de Sementes, vol. 28, no 2, p.15-25, 2006.

CARVALHO, N. M. de \& NAKAGAWA, J. Sementes: Ciência, Tecnologia e Produção. Campinas: fundação Cargil, 1980. 326 p.

CRAWLEY, M. J. Insect herbivores and plant population dynamics. Department of pure and Applied Biology, Imperial College, Silwood Park, Ascot, Berkshire, England SL5 7PY. In: revista Entomology, 1989. № 34: pag. 531 - 564.

FLORIANO, E. P. Armazenamento de sementes florestais. Caderno Didático no 1, 1a ed. Santa Rosa - RS, 2004.10 p.

GEHRING, C. 0 ambiente do trópico úmido e o manejosustentável dos agrossistemas. 2005.

HAU, C. H. Tree seed predation on degraded hillsides in Hong Kong. Forestry Ecology and Management, Amsterdam, v. 99, n. 1/2, p. 215 221, Dec. 1997.

LAMPRECHT, H. Ecossistemas Florestais e e respectivas espécies arbóreas (titulo original: waldbau in dentropen). EschobornRossdorf: TZ- Verl. - GES, 1990.

MATTEI, V. L. Importância de um protetor fisico em pontos de semeadura de Pinus taeda $L$. diretamente no campo. In: Revista Árvore, Viçosa - MG, v. 19, n. 3, p. 277 - 285, 1995.
MATTEI, V. L. \& ROSENTHAL, M. D. Semeadura direta de canafistula (Peltophorumdubium (Spreng.) Taub.) no enriquecimento de capoeiras. In: Revista Árvore, Viçosa - MG, v. 26, n6, p. $649-654,2002$.

MELATTI, J. C. Indios do Brasil. 7ạ Ed. São Paulo: AUCITEC; (Brasília): editora da UNB, 1993. 221 p. il.

OLIVEIRA, M. C. P. \& FERRAZ, I.D.K. Longevidade de propágulos de espécies florestais enterrados no solo da floresta e em áreas com diferentes graus de alteração, na Amazônia Central. In: Projeto Jacaranda - fase 2: pesquisas florestais na Amazônia Central / Org's: Niro Higuchi...[et al]. - Manaus: INPA, 2003.

OLIVEIRA, A. K. M.; SCHLEDER, E. D.; FAVEIRO, S. Caracterização morfológica, viabilidade e vigor de sementes de Tabebuia áurea (Silva Manso) Benth. \&Hook. f. ex. S. Moore.In: Revista Árvore, Viçosa - MG, v. 30, n, p. 25 32, 2006.

PENEIREIRO, F. M. Sistemas agroflorestais e pousio melhorado como alternativa a agricultura de corte e queima. In: Agrianual 2002 - Anuário da Agricultura Brasileira. Disponivel em:<http://www.agrofloresta.net/ bibliotecaonline/agrofloresta_cortequeima peneireiro.htm>.Acesso em 04/01/2005 às 15:37 h.

SANTOS Jr., N. A. Estabelecimento inicial de espécies florestais nativas em sistema de semeadura direta. Dissertação (Mestrado em Engenharia Florestal). Lavras: UFLA, 2000. 96p.

SHNEIDER, P. R.; FINGER, C. A. G. \& SHNEIDER, P. S. P. Implantação de povoamentos de dodonaea viscosa (1.) jacq. com mudas e semeadura direta.Ciência Florestal, Santa Maria, v.9, n.1, p.2933. 1999.

SILVA, A. R. M. Calagem para produção de 
mudas de mogno (Swieteniamacrophyllaking)

e sumaúma (Ceiba pentandra). Dissertação (Mestrado em Engenharia Florestal). Manaus: UFAM, 2004. 51 p.: il.

VERÍSSIMO, A. \& GROGAN, J. Síntese da situação do mogno em nível internacional. Brasília: Ministério do Meio Ambiente, 2002. 39 p.; $15 \times 21 \mathrm{~cm}$.

VIEIRA, A. H.; MARTINS, E. P.; PEQUENO, P. L. L.; LOCATELLI, M. e SOUZA, M. G. Técnicas de produção de sementes florestais. EMBRAPACPAF Porto Velho - RO: Ministério da Agricultura e Abastecimento.2001.

\section{AGRADECIMENTOS}

BARNI, P. E. obteve apoio do Conselho Nacional de Desenvolvimento Científico e Tecnológico - CNPq, através de Bolsa do Programa Institucional de Bolsas de Iniciação Científica - PIBIC, projeto №PIB-A-050/2004. Agradecemos a NASCIMENTO, J. P. e FERREIRA, F. F. pela ajuda indispensável no trabalho de campo e aos revisores anônimos. 